\title{
New cognitive info-communication channels for human-machine interaction
}

\author{
Csongor Márk Horváth \\ PPM AS, \\ Trondheim, Norway \\ csongor@ppm.no
}

\author{
Szilveszter Kovács \\ Department of Information Technology \\ University of Miskolc \\ Miskolc, Hungary \\ szkovacs@iit.uni-miskolc.hu
}

\begin{abstract}
The main goal of this paper is to discuss a new paradigm for robot teaching and supervising which is based on cognitive info-communication channels for human-machine interaction. According to the studied concept the robot is considered as an unskilled worker "who" (which) is strong and capable for precise manufacturing. "He" (it) has a special kind of intelligence, but "he" is handicapped in some senses, that is why "he" needs special treatment. We must command "him" clearly in a special way and we must supervise "his" work. If we can elaborate a proper way for communicating with this "new worker", as an additional dimension of robotization, we can get a capable new "colleague". The ultimate goal is to help the boss to be able to give the daily task to a robot in a similar way as he/she able to give the jobs to the human workers. For example, by providing the CAD documentation with some additional verbal explanation.
\end{abstract}

Keywords - cognitive info-communication, human-machine interaction

\section{INTRODUCTION}

\section{A. Motivation}

The main problem of robot teaching and supervising that it takes approximately 400 times longer to program a robot than to execute the actual task. Online programming is difficult, moreover the robot cannot produce anything during the online programming process. Hence there is a continuous demand for new and effective robot teaching methods.

If we use the robot as a manipulator to extend our working capability we usually need complex and very expensive sensors or feedback devices. Especially the force or tactile sensors and feedback devices are problematic and expensive. If we can develop a way for cheap and effective communication between the human operator and the robot, then we can extend the profitable robotization fields.

The European Union (EU) homes to more than 26 million companies of which $10 \%$ are manufacturing based. Out of these 2.5 million manufacturing companies, more than $95 \%$ of which are small medium enterprises SMEs, employ over 36 million people and contribute approximately $22 \%$ of the EU gross domestic product (GDP). In addition, it is estimated that in total around $75 \%$ of the EU GDP and $70 \%$ of employment in Europe is related to manufacturing as a direct result of manufacturing related service companies i.e. for every job in manufacturing there are two linked jobs in manufacturing related services. Therefore, any reduction in manufacturing capacity is likely to have a significantly negative socioeconomic impact. "An economy based on service industries alone will not survive in the longer term" (quote from the EC report 'MANUFUTURE - A Vision for 2020' [1]).

\section{B. ICT Transformation of Manufacturing}

Much work has already been done to identify which areas of info-communication technologies (ICT) will have the most impact on the future of manufacturing. The conclusions of the ManVis study [1] clearly states that ICT is a key cross cutting technology and that it is a fundamental foundation for improved competitiveness in the manufacturing industry. The ManVis final report suggests that competition from low wage economies will prevail in the foreseeable future. ICT can, however, minimize the inevitable decline of European manufacturing by cost reduction technologies such as automation and enhanced labour productivity. High technology manufacturing will be based on the efficient use of sophisticated manufacturing technologies, such as highly automated operations. This will be dependent on close links with the science base.

A long-range vision (15 years) has been formulated towards the development and use of industrial robotics in manufacturing scenarios of the future: The future family of industrial robots will support intuitive instruction, worker cooperation and rapid deployment.

\section{Needs of emerging robotics in end-user industries}

There are numerous new fields of applications and industrial branches in which robot technology is not widespread. The reason is the lack of flexibility, the challenging technical requirements and the high costs involved. New robotic applications will increasingly emerge from new industries and from SMEs, which cannot use today's inflexible robot technology or which still depend on manual operations under strenuous, unhealthy and hazardous conditions.

Relieving people from poor working conditions (e.g., operation of hazardous machines, handling poisonous or heavy material, working in dangerous or unpleasant environments) leads to new opportunities for applying robotics technology. Examples of poor working conditions can be 
found in foundries, the metal working industry. Besides the need of handling objects at very high temperatures, work under unhealthy conditions takes place in manual fettling operations, which contribute to about $40 \%$ of the total production cost in a foundry. Manual fettling means heavy lifts, strong vibrations, metal dust and high noise levels, resulting in annual hospitalization costs of more than $€ 150 \mathrm{~m}$ in Europe. Poor working conditions can also be found in slaughterhouses, fisheries and cold stores where low temperatures, hazardous tools and repetitive tasks contribute to unattractive working conditions. Other examples where robots can improve the working environment are painter workshops, glazier workshops and recycling plants.

If sensor information can be reliably used for robot control and if robot instruction schemes may be intuitive (e.g., by using more intuitive interaction mechanisms, built-in process knowledge and automatic motion generation), and the existing digital information can be easily accessed, then many applications areas, where the present robot technology has failed can be envisioned.

\section{ROBOTIC market}

Till now applications of robot automation technologies have been developed specifically for capital-intensive largevolume manufacturing resulting, in relatively costly and complex systems, which account for some $70 \%$ of all industrial applications; however, it is estimated that only $15 \%$ of possible applications are currently automated, with small and medium enterprises being particularly underrepresented. The world market peaked in 2005, reaching about 126,700 newly installed industrial robots, 30\% more than in 2004 [2]. This is the highest number ever recorded for one year. Nevertheless, developments were quite dissimilar in the three large industrial regions of Europe, America and Asia. While robotics investment boomed in Asia and America, order intakes in Europe were far more moderated. The automotive industry affected the results in all three regions. In Asia, in addition to the automotive sector, strong demand from the electronic components industry, the communication equipment industry and the computer industry reinforced the gain in market share already seen in 2004.

Europe is one of the world leaders in robotics equipment production and use; about $33 \%$ of worldwide yearly shipments, with a sale volume of about $€ 3.1$ billion, concerns European products; when considering industrial automation robotics' supply chain, annual sales volume growths up to about $€ 13$ billion. Robotics has been a major R\&D topic that was funded both at national and EU level. Industrial robotics research in Europe find a great support from the necessity expressed by more than 228,000 European small and medium sized industries of a more flexible and less bound to mass production automation technology; these necessities require future industrial robots to combine highest productivity and flexibility with minimal manufacturing equipment life-cyclecost.

\section{COGNITIVE INFO-COMMUNICATION CHANNELS FOR HUMAN MACHINE INTERACTION}

The concept discussed in this paper is rather different from the traditional human-machine interface approach, which try to provide the illusion of direct contact with the remote environment or the working pieces. Our approach is based on the fact that our brain extends and converts the information received by our sensory organs to a wide range of sensory representations. This cross-modal plasticity in cortical areas allows us to send different types of information to the brain via various different cognitive ways, so as we can interchange the sensory information between the human sensors. It is well known that when we recognize an image, only $10 \%$ of the total visual information comes from our eye, the remaining part is from our brain. Of course, it assumes a previous learning process. Our main challenge is that after a certain learning period we can "see" by the fingertips or by the ears (as the blinds can do it), we can "feel" tactile force or we can "listen" to a story by the eyes (as deaf people can do). Actually, this fact can be observed in many, everyday life situations as well. When someone tune the violin, he tunes, practically controls his hand, according to the information he experiences in his ears. A robot would measure the tenseness of the string and do the tuning based on that information. That we call as non-conventional communication (see in Fig. 1). The suggested concept opens new cognitive communication channels. For instance, force feedback can well be transferred to human by voices, which can be as helpful as the force feedback, but it is much cheaper sometimes it can be more efficient. In some cases, we do not need precise quantitative information, qualitative feedback is satisfactory.

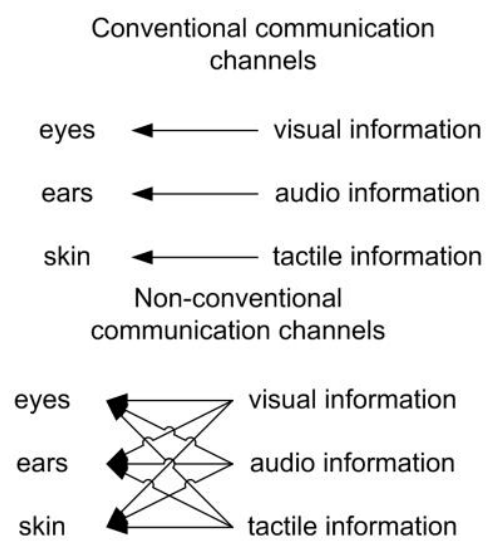

Fig. 1. Differences between conventional and non-conventional information channels

\section{INTELLIGENT SPACE AS A NEW PARADIGM IN HUMAN- MACHINE COMMUNICATION}

The Intelligent Space ("iSpace") is an intelligent environment which provides both information and physical supports to humans and robots to enhance their performances [3]. In order to observe the dynamic environment, many intelligent devices, which are called Distributed Intelligent Network Devices, are installed into the room as shown in Fig. 2. 
The DIND is a fundamental element of the iSpace. It consists of three basic components including sensors, processors and network devices. By communicating with each DIND [4], iSpace can perceive and understand events in the whole space. In addition to observation, the iSpace actuates intelligent agents such as mobile robots [5], computer devices and digital equipment. In order to enable humans to operate the agents in the iSpace, a suitable human interface is needed. For that reason, it has proposed the so-called "spatial memory" as an interface between human and the iSpace [6]. The spatial memory system enables human users to store computerized information into the real world by assigning a three-dimensional position to the information, and to retrieve the information by directly indicating the point using their own hands. Therefore, by using the spatial memory, human users are able to smoothly implement and utilize information and services in the iSpace by themselves.

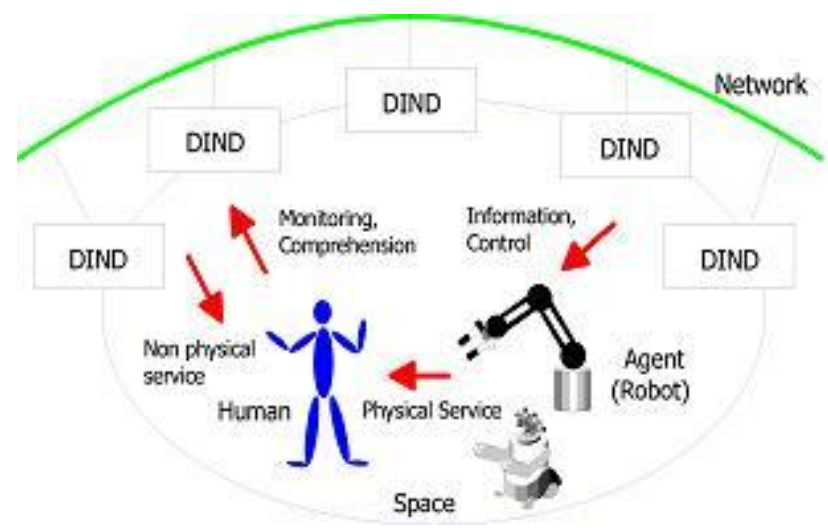

Fig. 2. Concept of the Intelligent Space

On the other hand, when we consider a situation in which the iSpace try to provide suitable services for humans autonomously, observation of human activities is more important. Human activities have been observed and analyzed through usage history of the spatial memory because information spatially arranged can be regarded as description of human activities in a certain environment. The observation approach provides us to distinguish human activities even in a same area without any knowledge about human activities. However, the approach cannot take into account interaction between humans and physical objects except for iSpace agents in the observation, because the spatial memory hasn't had a function to associate the stored information to physical objects but to three-dimensional positions. Meanwhile, we can assume that physical objects, which are used for users' daily life and used to accomplish their activities, are important to describe or estimate human activities. Therefore, we focus on physical interaction between humans and physical objects in order to more precisely and widely describe human activities.

There are several researches focusing on determination of physical objects. Nakauchi, et. al [7] estimate sequence of humans' cooking activities based on sequence of physical objects used. Nishida, et. al [8] have developed a language learning system which provides suitable information for users according to the position of physical objects. From these works, we can say that determination of physical objects and their position are useful to estimate human activities in the real world. Intelligent Space (iSpace) consists of three functions: "Observing", "Recognizing and Searching", and "Acting". Concretely, the iSpace offer appropriate service by understanding human intention and state in the space based on observation of space and human. In the Intelligent Space, the various sensor DINDs will be arranged such as cameras, laser range finders, microphones as well as these two sensing systems, and the information provided from them is vast. In order to utilize their information efficiently and usefully, a database to store information is needed. The system structure of the iSpace is shown in Fig. 3. The iSpace can guide the mobile robot moving in it [9].

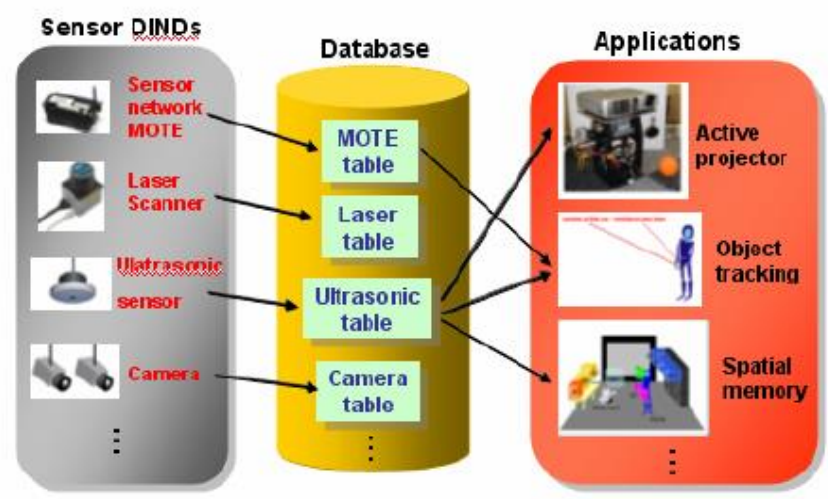

Fig. 3. Structure of Intelligent Space

\section{A. Spatial memory}

The spatial memory enables humans to store computerized information such as digital files and commands into the real world by assigning three-dimensional position as the memory address. Humans can retrieve and store such information by directly indicating the point using their own body, e.g. user's hand and user's head. That's why a point on user's body is called a human indicator. Fig. 4 shows a schematic concept of the spatial memory. The spatial memory system has the following advantages to achieve intuitively and instantaneously access and store computerized information. First, the users can arrange computerized information at a suitable location using their own eyes and own body action.
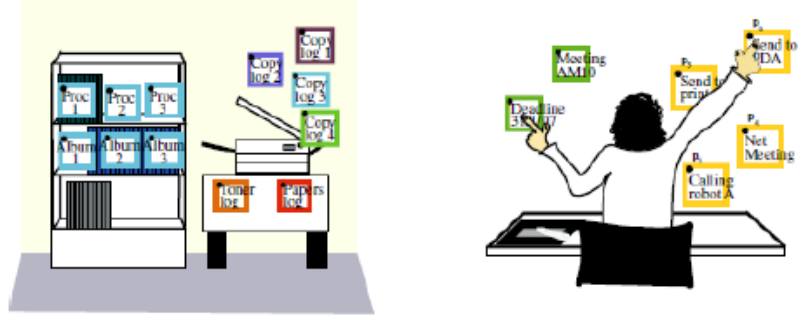

Fig. 4. Schematic concept of the spatial memory 


\section{B. System integration (Middleware technology)}

To manage a rapidly growing need for sensor communication in robotic applications several suitable architectures, named middleware's, is being developed for easy system integration. Unfortunately, most of these middleware technologies are developed independently of each other and are often dedicated for specific user applications [10]. In Table 1. the most important participants of the robot middleware competition are briefly compared.

TABLE 1. COMPARISON OF MIDDLEWARE TECHNOLOGIES [11]

\begin{tabular}{|c|c|c|c|}
\hline Name & $\begin{array}{l}\text { Middleware } \\
\text { technology }\end{array}$ & Open source? & $\begin{array}{c}\text { Relevant } \\
\text { contributors }\end{array}$ \\
\hline ASEBA & CAN & Yes & EPFL \\
\hline CLARAty & $\begin{array}{l}\text { Multi-level } \\
\text { mobility } \\
\text { abstraction }\end{array}$ & $\begin{array}{c}\text { Yes, but } \\
\text { some } \\
\text { restrictions }\end{array}$ & NASA \\
\hline Microsoft RS & $\begin{array}{c}\text { Web- } \\
\text { Services }\end{array}$ & No & Microsoft \\
\hline Miro & CORBA & Yes & $\begin{array}{c}\text { University of } \\
\text { California }\end{array}$ \\
\hline Orca & ICE & Yes & $\begin{array}{c}\text { KTH } \\
\text { Stockholm }\end{array}$ \\
\hline OrIN & $\begin{array}{c}\text { DCON, } \\
\text { SOAP, XML }\end{array}$ & $\begin{array}{c}\text { Yes, but } \\
\text { some } \\
\text { restrictions }\end{array}$ & JARA \\
\hline Open-R & Aperios OS & No & Sony \\
\hline Orocos & $\begin{array}{l}\text { RealTime } \\
\text { Toolkit }\end{array}$ & Yes & $\begin{array}{c}\text { Katholieke } \\
\text { Universiteit } \\
\text { Leuven }\end{array}$ \\
\hline Player & $\begin{array}{c}\text { Client / } \\
\text { Server } \\
\text { architecture }\end{array}$ & Yes & Multiple \\
\hline $\begin{array}{c}\text { RT- } \\
\text { Middleware }\end{array}$ & CORBA & Yes & AIST \\
\hline UPnP & $\begin{array}{c}\text { HTTP, } \\
\text { SOAP, XML }\end{array}$ & Yes & $\begin{array}{c}\text { University of } \\
\text { Coimbra }\end{array}$ \\
\hline Urbi & $\begin{array}{c}\text { Client / } \\
\text { Server } \\
\text { architecture }\end{array}$ & Yes & Gostai \\
\hline
\end{tabular}

Each of the above listed middleware solutions are composed from modularized components and have a hierarchical setup. The differences occur in the portability between different vendor's robots (how many robots are supported), the capability of adaptation to system changes (some are capable of plug-and-play discovery other need system restart), the way of communication between system components and the programming environment (contains integrated development environment or not).

Almost every competitor is capable of hiding low level robot programming (motor drives, sensor value read out, camera image access, etc.) and provides standard interfaces for high level object oriented robot programming.
The Japanese originated RT-Middleware is a middleware solution that is under standardization and also proved to be industry ready and adopted by many industrial partners (Toshiba (different system components), Honda (ASIMO humanoid robot), AIST (OpenHRP humanoid robot), etc.) and also many research institutes.

\section{Supervisory systems}

Manufacturing equipment undergoes continuous development as newer and better versions/solutions are pushed out into the market almost at a daily basis. To invest and keep pace with the newest technologies is a possibility of only a very few of the manufacturing companies. Small and medium sized enterprises (SME) cannot keep up with the investments, compared with their larger counterparts, and are facing special challenges.

During the last few decades much attention has been made to offline programming (generation and transfer of the numerical control code (NC-code)) of $\mathrm{CNC}$ machines. There exist three older basic standards for the generation of the numerical control (NC) code namely: ISO 6983, DIN66025 and RS274D [12]. The NC data, from these standards, are often referred to as $\mathrm{M}$ and $\mathrm{G}$ codes. Reported weaknesses from the usage of $\mathrm{M}$ and $\mathrm{G}$ codes are, among others [13]:

1) Low level language merely presenting the cutter location (motion) without any reference to the workpiece geometry. Creates very long code sets where editing is almost impossible.

2) Vendor specific supplements to the $M$ and $G$ codes are often out of the limited scope of the standard and in such cases the NC code will not be inter-machine exchangeable.

3) One way data flow from design to manufacturing. Experiences from the shop-floor are difficult to push back to the design stage.

As to overcome these shortcomings the ISO 14649 standard, often referred to as the STEP-NC standard, was derived from the initial work in the European Project OPTIMAL (ESPRIT III 8643) by the WZL of Aachen University in the middle of the 1990s [14]. In general, the STEP-NC is a new object-oriented model for data transfer between computer aided design (CAD) and computer aided manufacturing (CAM) systems. STEP-NC data transfer specifies the steps of the machining process rather than the cutter location (as for ISO 6983 systems) [15]. These higherlevel commands, describing the actual machining process, are by far more comprehendible, informative and interchangeable than the $\mathrm{G}$ and $\mathrm{M}$ - codes in use.

In order to transfer and/or distribute the generated machine code to the NC-machines a software solution named Direct Numerical Control or Distributed Numerical Control (DNCsoftware) has been developed by various manufactures. DNC programs are typically used to store larger $\mathrm{NC}$ program at separate computer, then the DNC will feed (upon request) the NC controller (which typically has a more limited memory capacity). Newer versions of DNC software features, among 
others, possibility to edit the $\mathrm{NC}$ code and a simplified visualization of the manufacturing process [16].

Recently modern NC-machines have the possibility for inter machine (I/O communication), typically targeted for communication with a shop-floor controller. However, this is a weaker feature in the history of development of NCmachines, compared to the development of offline programming tools and its appurtenant DNC software. Historically, in older machines there existed no prepared solution for inter-machine communication, so all the usual I/O signals (e.g. start spindle, stop spindle, open/close door/chuck) had to be captured individually from the controller by doing some-kind-of intervention on the $\mathrm{NC}$ controller itself. Also, some NC codes (M-codes) were dedicated for I/O communication (e.g. wait until confirmation etc). In general hardware intervention is a challenging task due to (very often) poor and limited documentation of the controllers. Reengineering of a controller is time consuming and all hardware intervention tasks carry the possibility for damages. Delivery times/cost for damaged components leads also to the minimization of any hardware intervention tasks.

The industrial robot is another key component in a FMC/FMS setup. Typically, industrial robots are used for material handling, replacing the human operator from repetitive/hard work tasks. Normally, these robots have excellent capability for I/O communication and are especially adapted for integration with other cell members. Thereby, in many smaller FMC setups we will find that the industrial robot acts as a cell controller. However, robots do not share the same language, even the same vendor often has different languages between different versions/types in their portfolio. In larger FMS system with several robots doing different work tasks the possibility that all robots are similar in kind and language will be very limited. Anyway, robots and NCmachines do not share the same language and software communication between these two groups of machines is often non-existent. Again, this leads to more specialized solutions to be derived from case to case and all communication is normally done on a hardware level with dedicated I/O ports where the typical NC-machine has limited functionality.

\section{COGNITIVE INFO-COMMUNICATION CHANNELS FOR HUMAN MACHINE INTERACTION}

One of the main challenges in supervisory control is to transfer the sensory environment of the robot to the supervisor. Namely, the supervisor would like "to be present" in the process as much as possible. There are basically two problems here. Firstly, the process may need the optimization, or subcontrol of physical signals for which a human operator does not possess sensors (for instance the measurement of current during welding). Secondly, the operator may require other, supplementary signals to understand the process. In other words, he/she can sense reality much more precisely using his/her learned $6^{\text {th }}$ or $7^{\text {th }}$ sense, a mechanism that is not really applicable in automated control (for instance, when the pilot hears the engine of the racing car and feels the acceleration in his body and sees the moving environment around him at the same time, then after some practice he can easily optimize the engine's power; while a computer would probably measure the inertia and rpm of the engine instead to control the acceleration). We should emphasize here that in many cases humans can learn and connect their understanding to the physical measurement system, however, we have to find the best channel for this communication. Such channels were already recognized, for instance, when choosing between digital and analogue representations of measured details. It is well known that the pilot in an airplane, who is forced to take into consideration many details at the same time, prefers to use an analogue representation in most cases even though it is not as precise as a digital number on the screen. We also should underline here that each supervisor may have different professional channels for process control (a professional cellist can tune his/her cello to perfection very easily, while other individuals may have more trouble in such cases and may refer to the support of electronic tuning devices which provide a visual evaluation output). We may therefore conclude that humans use cognitive sensing and, therefore, communication with the process to be controlled can hardly or cannot be broken down to typical robot sensor systems, not even by measuring (or simply conjecturing) all the necessary details. We have to develop a cognitive transfer mechanism to improve and specialise communication channels.

\section{A. Possible research and development goals}

Therefore, various cognitive communication channels are needed to be developed that can be easily combined under the middleware platform and fit to the robot sensor system according to the special capabilities of the operator (as a matter of fact the operator should need practice to use the communication channel to perfection). For instance, an operator who has a good sense of hearing can use his/her ears rather than eyes to understand distances (note the difference between tuning a cello using the ears or using an electronic tuning device).

The cost of establishing the developed communication channels are also needed to be considered. For instance, force feedback can classically be implemented mechanically, as shown in Fig. 5. This system has a limited degree of freedom in comparison to a human being, and it is very expensive. From a theoretical point of view, it is also complicated since we need to compensate the weight of the system in each position in case of zero force-feedback and it should be modified according to geometrical specifics dictated by the user. It is also important to note that this system is not easily portable and its deployment is also complicated. However, the force feedback can be easily transformed via cognitive channels such as sounds and vibrations [17] (or even more effectively using a combination of these) and then transferred to humans depending on the task to be accomplished. These tools are much cheaper and simpler, see Fig. 6, furthermore would be much more comfortable. In the same way, the temperature detected on the arms and body of the worker can easily be transferred via vibration tools put on the arms of the user. 


\section{B. System integration (Middleware technology)}

The robot middleware framework can be easily be adapted and extended to include the typical components of an FMC(S) system like industrial robots, CNC machines, automated guided vehicles (AGVs) etc. Preferably these machines should be "broken down" to the lowest system level (in general to the motor controller) and middleware components (device drivers) needed to be developed, followed by a task dependant assembly and programming. This will create a truly flexible system where it is possible to control all the actions within machines and their interactions with the other members. It would be possible to merge two or more machines and achieve a full coordinated control. As an example a 6- axis robot could be merged with a 3-axis NC-machine into a 9 axis machine with the possibility of a synchronous machining/ handling of the work piece.

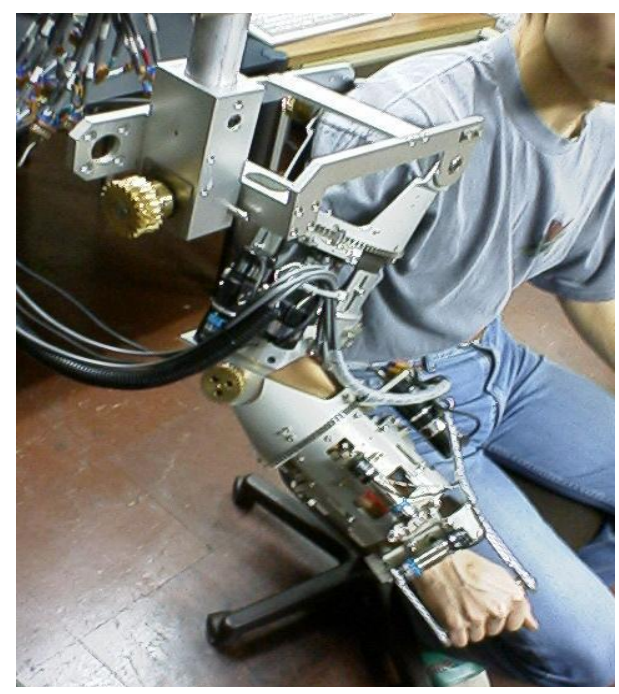

Fig. 5. Classical force feedback system
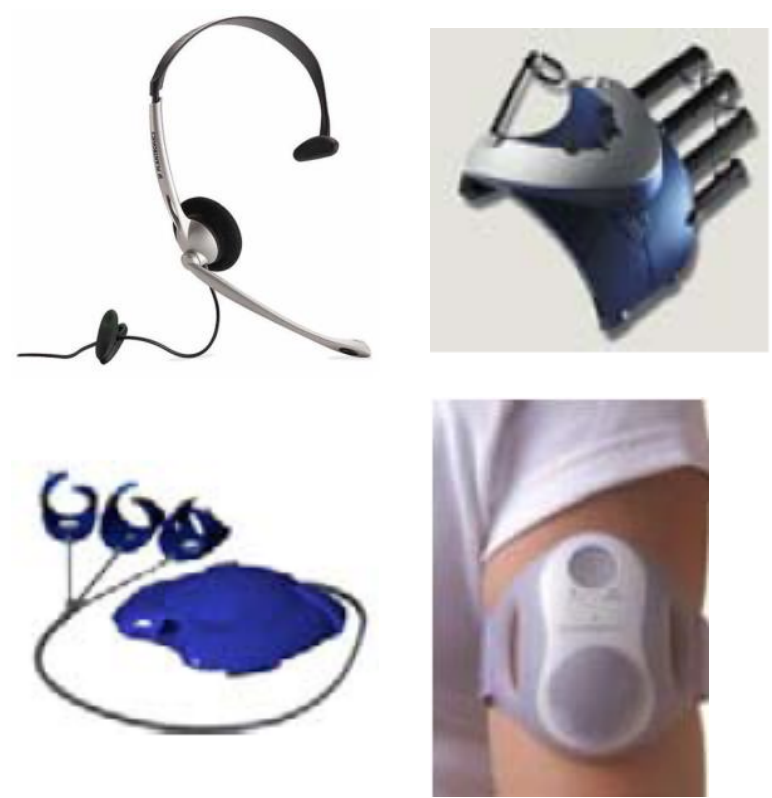

Fig. 6: "simple" tools for cognitive channels
However, a complete system "break down" will, in many cases, be very challenging to achieve because of the week documentation in older machines. In such cases the system "break down" and the development of the device drivers should be stopped at a level where the necessary data can be retrieved. Fig. 7. shows the conceptual layout of a FMC system were RT-Middleware components exist in different levels [18]. RTCs can be merged to become a higher level RTC or it can be used "as is" in the cell controller. As the work task requirements changes the structure can be remodelled and if necessary a deeper system intervention and development of lower level RTCs could be carried out.

By using a CORBA based software controller (also introduced by J. Shin, S. Park, C. Ju, H. Cho [19]), and device drivers (also introduced in the comprehensive work of $\mathrm{H}$. Van Brussel and P. Valckenaers [20]) this architecture will be highly flexible and suitable for low series production in the SME sector.

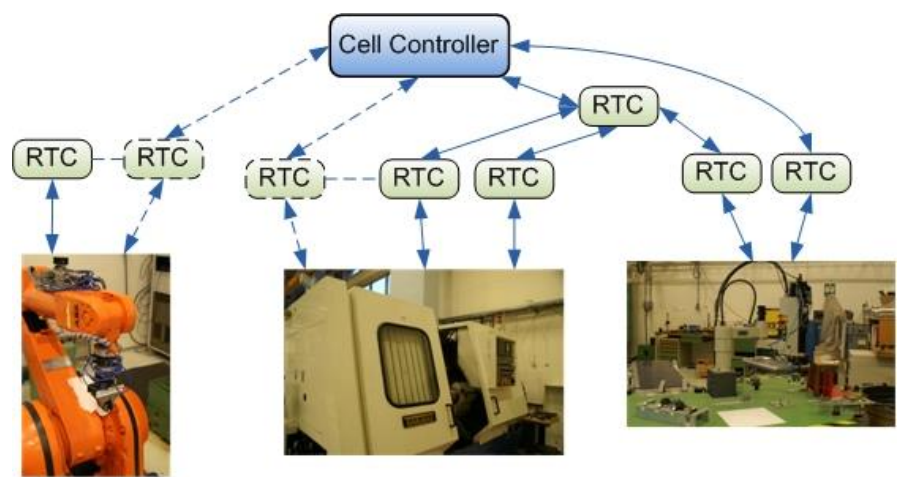

Fig. 7. Component based system setup [18]

\section{The supervisory system}

An industrial robot usually works in a production line. The robot is programmed once and the program is repeated over a thousand times. In case of grinding and deburring applications, usually the robot has to be reprogrammed based on individual observation of every workpiece. Reprogramming the robot with Offline programming each time is not acceptable, as it is time consuming and needs highly qualified operators. Usually grinding and deburring is carried out by not so qualified people, who are capable of doing tedious and monotonous work in hard and unhealthy work-environment.

Using an industrial robot for grinding and deburring, which is at least as punctual as the human, would be a good alternative in the above mentioned application. A fully automated grinding or deburring system would be expensive and the overall result could be worse than in case of the manual grinding or deburring. Utilizing the experience from manual grinding, an operator helped with a $90 \%$ automated system will result in the best efficiency, healthier working environment, higher production number and less cost. The methodology of Supervised and adaptive programming of Industrial Robots [21] is shown in Fig. 8. 
The image from the camera is passed through many filters to help the operator in error identification. The operator's task is to identify the errors (burrs, irregularities) of workpiece in the image provided by the camera. Error identification is done by the operator by drawing lines, curves or regions on the image. The Operator is involved only in this task; all other system components are fully automated (Robot program generation, robot program compile, robot program upload).

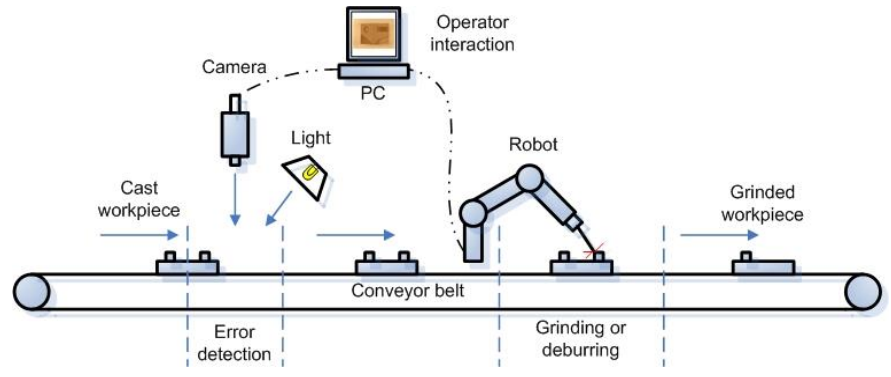

Fig. 8. Industrial use of SAPIR [21]

\section{The teaching methods}

In manufacturing engineering, man-machine interaction has gone from typical online programming techniques into virtual reality based offline programming methodologies. Today, a wide range of offline software tools is used to imitate, simulate and control real manufacturing systems. However, also these new methodologies lack capability when it comes to human-machine communication. Typically, today communication with the virtual environment is done via a keyboard/mouse interface while feedback to the operator is given from the computer screen. These desktop reality systems uses only a limited spectre of human senses and there is quite a low sensation of "being inside" the system. Programming is still done on the premises of the machines.

By introducing modern technologies, like motion capturing and augmented reality principles, with the goal of adding human representations into the programming environment it will be possible to create a new programming concept where the human operator can interfere with machines in a cognitive manner. Thus, the knowledge of a skilled operator is needed to be captured and an automatic knowledge transfer can program the robot system [22].

This case the human operator can freely move around in an industrial environment (e.g. shop-floor) and identify the workpieces which are necessary to modify via some robot action. As before mentioned, such a typical situation could be a robot grinding process following a molding process where the workpieces suffer from some irregularities (burrs). By sight, the human operator can so very easily identify the area of problem but cannot exactly quantify the error in term of necessary material removal to reach the ideal final geometry.

After work-piece identification, the next step in interactive robot programming is to let the operator make a decision on what kind of machining action is necessary to undertake. Naturally, larger modifications with several machining passes requires a more detailed analysis and often leads to selecting other machinery than a robot for the machining process (e.g. milling- or turning- machine). On the other side, if the cutting depth and material removal is moderate the robot can serve as an excellent alternative.

Assuming the selection of robot machining, the next step is to capture the machining path. Here the human operator e.g. can just move his finger, hand, or arm over the region of interest while a motion capture system will store all its movements.

The path from the motion tracking system must be transferred onto to the ideal work piece (e.g. CAD-model) in order to verify that the path actually is located as expected. The path is automatically projected (as a line) onto the surface of the CAD model. By transferring the robot path directly onto the CAD model actually defines what the final end-geometry should look like after the manufacturing process. By this the risk of cutting into the final geometry is reduced. At a later stage, before starting up the actual machining process the mean cutting depth can be calculated (indicated) by a few "Teach" point along the path which again, based on the material characteristics in the work-piece and cutting tool, gives an answer if more than one machining pass is necessary.

Further, the line from the CAD model is fed-back to the operator either through a (handheld) computer screen or as suggested via an augmented virtual reality system in the sense of a Head Mounted Display (HMD). This ability of instant feed- back makes it possible for the operator to relocate his path according to what he sees at the real work-piece. By placing the operator "into the loop" of adjusting/relocating the generated path, the accuracy requirements of the motion capturing module are minimized.

Before machining can start, the work- piece base coordinate system must be established with respect to the robot base coordinate system. The accuracy of the machining process will greatly depend on the quality of this work. Also, simulations of the complete robot motions can be undertaken in order to check for singularities, out of range limitations, and possible collisions [23].

Finally, the machining process can be executed. As mentioned above cutting depth calculations may be undertaken in order to verify that the operation is done within certain limits of the machinery.

\section{CONCLUSION}

Typically, industrial robots are used as transporting devices (material handling of work pieces between machines) or in some kind of additive- (e.g. welding, painting etc.) or subtractive- manufacturing process (e.g. grinding, deburring etc.). Also, the industrial robot controller has good capability of I/O communication and often acts as cell controller in a typical set-up of a flexible manufacturing cell or system. Thus, in advanced manufacturing systems the industrial robot serves as a key component for coordinated control and effective utilisation of the complete production unit.

However, in many regions there are a very low number of industrial robots in use. The reason is the fact that modern 
manufacturing equipment are mainly developed for larger production series than it is typical in SME environment. In smaller series production standard equipment (robots) are just too time-consuming when it comes to reprogramming and path adjustments.

Also from a technical point of view, robot technology needs to be adapted to new advanced application areas (e.g. machining) in small series production units. As an example, the programming time of a robot grinding path is 400 times the execution time. This clearly indicates the need for a certain lot size. This leads to the conclusion that methodologies for initial programming and process variable adjustment of the robot trajectory must be focused, as to create more rapid, interactive and human friendly systems.

In recent years, significant amounts in dollars, euros and yen have been invested, both nationally and internationally, in the development of increasingly advanced robots that can, independently or in interaction with humans, perform increasingly complex tasks and functions.

However, intelligent robots are not just entertainment to captivate, or perhaps frighten, us. Robot technology has an extremely wide range of applications, and users are formulating promising perspectives for innovation. For instance, intelligent technological toys, advanced welding robots, robots for tending to animals in the agricultural sector, robots for complicated surgery at hospitals, robots that can navigate and collect samples on Mars or robots that can understand and respond to human speech.

There is probably no doubt that increasingly advanced robots and intelligent products will be developed in the future. But technical intelligence still leaves a lot to be desired. To date, we have only been able to produce robots that are programmed to perform repetitive tasks with a series of specific movements and functions. Advanced robots are not only a question of technology and intelligence. Increased utilisation of robot technology can also lead to a need for debate on the ethical and societal aspects resulting from the way robot technology will affect our daily lives - both at home and at work.

The manufacturing industry is often faced to the problem of rapid product renewal, production processes with large variations and small series, which place demands on flexible production lines with short change-over times. So there is need for advanced cognitive robots, that are flexible and that can quickly be recalibrated for other production series.

An important key concept for robots will be production cells that consist of machinery, equipment, sensors, robots and operators. And there will be the need and opportunity to make integration and communication between the various elements of a cell more efficient and targeted towards varied one-off production and a high degree of process variation. Furthermore, there will be a need to develop intelligent user interfaces that can promote interaction between robots and operators and that can help the user to quickly and flexibly understand a new task.

\section{ACKNOWLEDGEMENT}

The project acknowledges the financial support of Hungarian Research Fund (OTKA K120501).

\section{References}

[1] European Commission. Directorate General for Research, MANUFUTURE High Level Group, "MANUFUTURE: A Vision for 2020 : Assuring the Future of Manufacturing in Europe", 2004.

[2] International Federation of Robotics (IFR), [Online],"World Robotics 2007',

http://www.worldrobotics.org/downloads/2007_Executive_Summary.pd f, 2007

[3] Korondi P, Hashimoto H,'Intelligent space, as an integrated intelligent system" Proceedings of the 15th International Conference on Electrical Drives and Power Electronics EDPE-2003. pp. 24-31,2003

[4] Yoshihisa Toshima, Noriaki Ando and Hideki Hashimoto, "Information Display System using Active Projector in Intelligent Space -Integration of distributed devices based on RT-Middleware", The 12th International Sysmposium on Artificial Life and Robotics (AROB'07), pp.183-186, 2007

[5] Baranyi Peter, Nagy Istvan, Korondi Peter, Hashimoto Hideki, "General guiding model for mobile robots and its complexity reduced neuro-fuzzy approximation" in Proceedings of 9th IEEE International Conference on Fuzzy Systems, pp. 1029-1032, 2000

[6] Mihoko Niitsuma, Hiroshi Hashimoto, Hideki Hashimoto, "Spatial Memory as an Aid System for Human Activity in Intelligent Space", IEEE Transactions on Industrial Electronics, Vol.54, No.2, pp.11221131, 2007

[7] Y.Nakauchi, T.Fukuda, K.Noguchi, T.Matsubara, "Intelligent Kitchen: Cooking Support by LCD and Mobile Robot with IC-Labeled Objects", Proc. of the 2005 IEEE/RSJ Int. Conf. on Intelligent Robotics and Systems, pp.2464-2469, 2005

[8] Y. Nishida, M. Hiramoto, F. Kusunoki, H. Mizoguchi, "Learning by Doing: Space-Associate Language Learning Using a Sensorized Environment", in Proc. of IEEE Int. Conf. on Intelligent Robots and Systems, pp. 1583-1588, 2005

[9] Mizik S, Baranyi P, Korondi P, Sugiyama M, „Virtual Training of Vector Function based Guiding Styles" Proc. of Scientific Bulletin of Politehnica University of Timisoara, Transactions on Automatic Control and Computer Science 46(60):(1), pp. 81-86, 2001

[10] Tetsuo Kotoku, "Robot Middleware and its Standardization in OMG" in International Conference on Intelligent Robots and Systems (IROS'06) Workshop on Robotic Standardization, Beijing, China, 11-13 Oct. 2006

[11] B. Solvang, G. Sziebig and P. Korondi, "Multilevel Control of Flexible Manufacturing Systems", in Proc. of Conference on Human System Interaction, 2008

[12] Y. Liu, X. Guo, W. Li, K. Yamazaki, K. Kashihara, M.Fujishima, "An intelligent NC program processor for CNC system of machine tool," in Robotics and Computer-Integrated Manufacturing, vol. 23, Elsevier, pp. 160-169, 2007

[13] X. Zhu, Y. Wang, H. Fu, "A 3-D Simulation System for Milling Machining Based STEP-NC" in Proceedings of the 2006 IEEE International Conference on Mechatronics and Automation, Dalian, China, 2006

[14] S.H. Suh, B.E. Lee, D.H. Chung, S.U. Cheon, "Architecture and implementation of a shop -floor programming system for STEPcompliant CNC" in Computer-Aided Design, vol. 35, Elsevier, pp. 1069-1083, 2002

[15] Sibul Lazar, Sziebig Gabor, Korondi Peter, „Review of Man-Machine Interaction in Five-axis Machining with STEP-NC", IFAC PAPERS ONLINE 48:(19) pp. 166-171, 2015

[16] Solvang Bjørn, Sziebig Gábor, Korondi Péter, „Vision Based Robot Programming", IEEE International Conference on Networking, Sensing and Control (ICNSC 2008). pp. 949-954, 2008 
[17] Sziebig Gábor, Solvang Bjørn, Kiss Csaba, Korondi Péter, "Vibro-tactile feedback for VR systems" in 2nd International Conference on Human System Interaction (HSI), pp. 406-410, 2009

[18] Bjorn Solvang, Gábor Sziebig, Péter Korondi, "Shop_Floor Architecture for Effective Human-Machine and Inter-Machine Interaction", ACTA POLYTECHNICA HUNGARICA 9:(1) pp. 183-201, 2012

[19] J.Shin, S.Park, C.Ju, H.Cho, "CORBA-based integration framework for distributed shop floor control" in Computers \& Industrial Engineering, vol. 45, Elsevier, pp. 457-474, 2003

[20] H. Van Brussel, P. Valckenaers, "Robotics, FMS and CIM" in Handbook of Industrial Robotics, edited by S.Y. Nof, 2nd edition, John Wiley \& Sons INC, New York, ISBN-0-471-17783-0, pp. 811-824, 1999
[21] Solvang Bjørn, Korondi Péter, Sziebig Gábor, Ando Noriaki SAPIR: Supervised and Adaptive Programming of Industrial Robots, 11th IEEE International Conference on Intelligent Engineering Systems (INES 2007), pp. 281-286, 2007

[22] Husi G; Szász C; Chindris V: Artificial Immune System Implementation upon Embryonic Machine for Hardware Fault-tolerant Industrial Control Applications Journal Of Computer Science And Technology (ISSN: 1000-9000) (eISSN: 1860-4749) 10: (4) pp. 60-66. (2010)

[23] Husi G: Position Singularities and Ambiguities of the KUKA KR5 Robot International Journal Of Engineering And Technology Research 1: (1) pp. 44-50. (2015) 